\title{
Potential Impact of COVID-19 on Recently Resettled Refugee Populations in the United States and Canada: Perspectives of Refugee Healthcare Providers
}

\author{
Sarah K. Clarke ${ }^{1}(1) \cdot$ Gayathri S. Kumar $^{2} \cdot$ James Sutton $^{3} \cdot$ Jacob Atem $^{4} \cdot$ Anna Banerji $^{5} \cdot$ Mahli Brindamour $^{6}$. \\ Paul Geltman ${ }^{7} \cdot$ Najah Zaaeed $^{8}$
}

Accepted: 1 October 2020 / Published online: 16 October 2020

(c) Crown 2020

\begin{abstract}
Recently resettled refugee populations may be at greater risk for exposure to severe acute respiratory syndrome coronavirus 2 (SARS-CoV-2), a virus that causes coronavirus 2019 (COVID-19), and face unique challenges in following recommendations to protect their health. Several factors place resettled refugees at elevated risk for exposure to persons with COVID-19 or increased severity of COVID-19: being more likely to experience poverty and live in crowded housing, being employed in less protected, service-sector jobs, experiencing language and health care access barriers, and having higher rates of co-morbidities. In preparing for and managing COVID-19, resettled refugees encounter similar barriers to those of other racial or ethnic minority populations, which may then be exacerbated by unique barriers experienced from being a refugee. Key recommendations for resettlement and healthcare providers include analyzing sociodemographic data about refugee patients, documenting and resolving barriers faced by refugees, developing refugee-specific outreach plans, using culturally and linguistically appropriate resources, ensuring medical interpretation availability, and leveraging virtual platforms along with nontraditional community partners to disseminate COVID-19 messaging.
\end{abstract}

Keywords Resettled refugee $\cdot$ COVID-19 $\cdot$ Recommendations $\cdot$ Resettlement $\cdot$ Primary care $\cdot$ Health disparities $\cdot$ Culturally and linguistically appropriate services $\cdot$ Healthcare access $\cdot$ Language and cultural barriers

Recently resettled refugee populations may be at greater risk for exposure to SARS-CoV-2, the virus that causes coronavirus 2019 (COVID-19), and face unique challenges in following recommendations to protect their health. Data on the prevalence of COVID-19 among resettled refugee

Disclaimer: The findings and conclusions in this report are those of the authors and do not necessarily represent the official position of the Centers for Disease Control and Prevention.

Sarah K. Clarke

sarah@refugeesociety.org

1 Society of Refugee Healthcare Providers, 134 Douglas Glen Park SE, Calgary, AB T2Z 3Z3, Canada

2 Centers for Disease Control and Prevention, Society of Refugee Healthcare Providers, Atlanta, GA, USA

3 Society of Refugee Healthcare Providers, Rochester, NY, USA

4 Society of Refugee Healthcare Providers, Gainesville, FL, USA populations in the United States and Canada are currently lacking. While there is a lack of data on refugees, recently resettled refugees have several risk factors that place them at elevated risk of exposure to SARS-CoV-2 or severe illness from COVID-19, such as being more likely to experience poverty and live in crowded housing, being employed in less protected, service-sector jobs, experiencing language and health care access barriers, and having higher rates of

5 Society of Refugee Healthcare Providers, Pediatrics and Dalla Lana School of Public Health, University of Toronto, Toronto, ON, Canada

6 Society of Refugee Healthcare Providers, Saskatoon, SK, Canada

7 Society of Refugee Healthcare Providers, Boston, MA, USA

8 Society of Refugee Healthcare Providers, Syracuse, NY, USA 
co-morbidities [1]. Recent data suggest a disproportionate burden of illness and death among other racial and ethnic minority populations [2].

In preparing for and managing COVID-19, resettled refugees encounter similar barriers to those of other racial or ethnic minority populations, which are then exacerbated by unique barriers experienced from being a refugee. In the early resettlement period, refugees encounter multiple potential stressors and competing priorities, such as adjusting to a new country, finding employment, learning a new language, and navigating complex, unfamiliar healthcare systems [3]. Unaccompanied refugee minors-that is, children without a parent or guardian to help care for them-have the stress of adjusting to new caregivers and the foster care system. Even before the pandemic, inadequate access to health information and culturally and linguistically appropriate services, especially within healthcare, has led to health disparities and worse health outcomes for refugees [4]. Other unique cultural factors that can affect resettled refugees' ability to cope with this pandemic include the ability of refugees to access health information, their expectations and understanding of the United States and Canadian healthcare systems, their employment rights, and access to refugee-specific services.

Challenges resettled refugees face are similar to other disproportionately affected groups, such as low-income Canadians and US residents. Low health literacy, reduced community social support and family separations, potentially complex medical or mental health conditions, and inadequate access to reliable transportation and healthcare facilities can also place resettled refugee populations at increased risk for COVID-19. These challenges are compounded by the pandemic mitigation efforts of quarantines, shelter-in-place orders, travel bans, and closures of vital government and community services [5]. Refugees may also be more likely to serve as critical workers in essential industries and manufacturing, where physical distancing may be difficult to achieve and protective measures may be lacking. For example, outbreaks of COVID-19 in the United States and Canadian meat and poultry processing facilities employing refugee and immigrant worker populations have already been reported [6]. Fear, stigma, discrimination, and the need to work due to difficult economic circumstances may negatively impact refugees' ability to be tested or seek care for suspected COVID-19 symptoms [7].

Resettled refugees are also at risk for the development or progression of some communicable or non-communicable diseases as a result of not seeking timely medical care during the pandemic. Soon after resettlement, refugees typically receive a medical examination during which available medical records are reviewed, a physical examination is conducted, diagnostic screening tests ordered, and vaccinations are administered [1]. On arrival in their new country, many refugees may not vaccinated or are under-vaccinated according to national guidelines due to reasons such as inadequate access to or unavailability of vaccines in the countries from which they emigrated. However, most USresettled refugees should have received at least one dose of Measles, Mumps, and Rubella (MMR) vaccine and other recommended vaccines [8]. However, these initial examinations may be delayed in the setting of the pandemic. Lack of health screening on arrival could place refugees at higher risk for vaccine-preventable diseases like measles, which has seen a resurgence in recent years with over 400,000 cases reported worldwide in 2019 [9]. Fear of exposure to SARS-CoV-2, language barriers, and the inability to access telehealth services may also prevent refugees from seeking medical care for management of other illnesses and for routine preventive care such as childhood immunizations.

To mitigate the risk of COVID-19 for refugees, communications and guidance regarding COVID-19 symptoms, prevention, self-management and how to safely access care can be provided by multiple partners working with refugees. These partners include resettlement agencies, state refugee health coordinators, refugee community organizations, health departments and individual health care providers. Since resettlement agencies are typically the first groups to engage with refugees after arrival, they play an important role in educating refugees about how to protect themselves from COVID-19. Health promotion initiatives in collaboration with different partners using culturally and linguistically appropriate resources (Table 1) can incorporate information about COVID-19 and how to manage and access care for other health needs (e.g., mental health, non-communicable diseases, vaccinations).

Because refugee resettlement services are limited in time and scope, and it is possible for resettled refugees to become lost to follow-up within healthcare systems, health departments and healthcare providers working with refugee populations could actively implement refugee-specific outreach plans. These plans can be informed by their communities' or patients' demographics with the assistance of trusted community members such as community health workers. Again, engaging with key partners such as refugee community organizations would facilitate this effort. Virtual platforms such as social media can be used to help implement these initiatives especially through partnerships with health professionals who are formerly resettled refugees, although these platforms may be less accessible to individuals with disabilities [10]. Individuals working with refugees could seek to understand barriers (including cultural, social and economic) that increase the risk of acquiring SAR-CoV-2, and then work with resettlement agencies and other key partners to ensure that these barriers are addressed. Healthcare providers could capitalize on community health workers, patient navigators and other patient advocates to ensure regular and frequent communication with refugees who 
Table 1 COVID-19 Resources for health professionals working with resettled refugee populations in the United States or Canada

\begin{tabular}{|c|c|c|}
\hline Topic & Organization & Link \\
\hline \multirow[t]{5}{*}{ Health guidelines } & US Centers for Disease Control and Prevention & $\begin{array}{l}\text { https://www.cdc.gov/coronavirus/2019-nCoV/hcp/index } \\
\text {.html } \\
\text { https://www.cdc.gov/coronavirus/2019-ncov/need-extra } \\
\text {-precautions/refugee-populations.html } \\
\text { https://www.cdc.gov/coronavirus/2019-ncov/commu } \\
\text { nication/print-resources.html?Sort=Date\%3A\%3Ades } \\
\text { c\&CDC_AA_refVal=https\%3A\%2F\%2Fwww.cdc. } \\
\text { gov\%2Fcoronavirus\%2F2019-ncov\%2Fcommunication } \\
\text { \%2Ffactsheets.html\&Page=2 }\end{array}$ \\
\hline & US National Institutes of Health & https://covid19treatmentguidelines.nih.gov/ \\
\hline & Public Health Agency of Canada & $\begin{array}{l}\text { https://www.canada.ca/en/public-health/services/diseases/ } \\
\text { coronavirus-disease-covid-19.html }\end{array}$ \\
\hline & American Academy of Pediatrics & $\begin{array}{l}\text { https://services.aap.org/en/pages/2019-novel-coronaviru } \\
\text { s-covid-19-infections/ }\end{array}$ \\
\hline & Canadian Pediatric Society & $\begin{array}{l}\text { https://www.cps.ca/en/tools-outils/covid-19-informatio } \\
\text { n-and-resources-for-paediatricians }\end{array}$ \\
\hline Partner organization & Association of Refugee Health Coordinators & $\begin{array}{l}\text { https://refugeehealthcoordinators.wordpress.com/ } \\
\text { https://www.acf.hhs.gov/orr/resource/orr-funded-progr } \\
\text { ams-key-contacts }\end{array}$ \\
\hline \multirow{4}{*}{$\begin{array}{l}\text { Information on COVID-19 in } \\
\text { multiple languages }\end{array}$} & Society of Refugee Healthcare Providers & https://refugeesociety.org/covid-19-resources \\
\hline & $\begin{array}{l}\text { COVID-19 Health Literacy Project in partner- } \\
\text { ship with Harvard Health Publishing }\end{array}$ & https://covid19healthliteracyproject.com \\
\hline & Switchboard & $\begin{array}{l}\text { https://switchboardta.org/blog/a-round-up-of-multilingu } \\
\text { al-resources-on-covid-19/ }\end{array}$ \\
\hline & Cultural Orientation Resource Exchange & https://coresourceexchange.org/covid-19-resources/ \\
\hline \multirow[t]{2}{*}{ Workers' rights during COVID-19 } & Government of Canada & $\begin{array}{l}\text { https://www.canada.ca/en/government/publicservice/covid } \\
\text {-19/rights-responsibilities.html }\end{array}$ \\
\hline & US Department of Labor & https://www.dol.gov/agencies/whd/flsa/pandemic \\
\hline
\end{tabular}

become ill with COVID-19. Medical interpretation services should be provided for refugees who need them during at all healthcare visits and communications. ProPublica has reported about overwhelmed US hospital systems unable to use interpreters when speaking with patients and their families [11]. During the pandemic when telephone or video interpretation services are more likely to be used than inperson interpretation services, technological concerns and the enhanced time burden associated with these services can complicate effective communication. Healthcare providers, with assistance from resettlement agencies and/or the state refugee health coordinator, should work with health system administrators to ensure that appropriate interpretation services are available for patients with limited English proficiency to optimize patient communication.

Refugees may not consistently voice their concerns in following COVID-19 prevention and/or self-management recommendations to their resettlement case managers or healthcare providers. This could be for many reasons including lower health literacy, lack of awareness of the preventative and supportive role of the healthcare provider, or mistrust of the health system [12]. Therefore, individuals working with refugees can play a critical role in proactively assessing the following with refugee patients: their understanding of COVID-19; how they access information about COVID-19 and their preferred method of receiving health information (e.g., traditional media, social media); their capacity to maintain physical distancing and follow safe preventive practices within their household; their sources of support if they need to seek medical attention or access essential needs like groceries and medications; their understanding of how to access healthcare if needed; their access to safe and reliable transportation if they need to seek care; their location of employment and if safe procedures to prevent exposure are in place and are being followed; and their preferred method of communication with healthcare providers. Furthermore, health systems and refugee-serving organizations need to ensure that providers and staff are culturally responsive, as this may help build trust with their patients or clients.

Those engaging refugee populations should continue to plan and prepare for SARS-CoV-2 transmission among refugees, their communities, and places of employment.

We offer key strategies (Table 2) for healthcare settings and providers to assist with planning. In collaboration with partners, including health departments and state refugee health coordinators: 


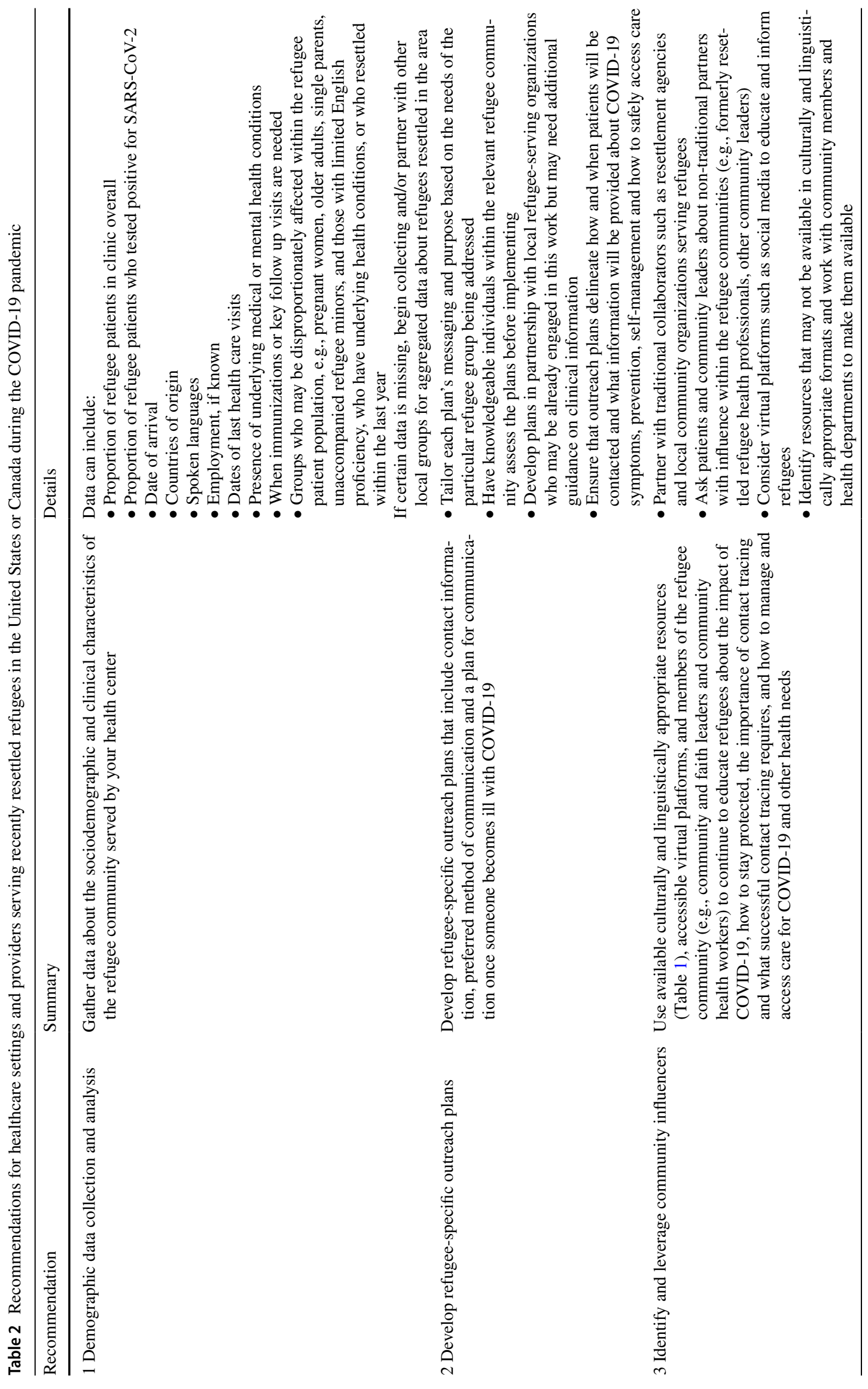


- Gather data about the sociodemographic (including spoken languages) and clinical characteristics of the refugee community served by your clinic.

- Ensure that medical interpretation is available for each patient encounter for those refugees that need it.

- Seek to understand and resolve barriers that prevent refugees from following COVID-19 prevention recommendations and accessing care.

- Develop refugee-specific outreach plans that include contact information, preferred method of communication and a plan for frequency of communication once someone tests positive for SARS-CoV-2.

- Use available culturally and linguistically appropriate resources (Table 1), accessible virtual platforms, and members of the refugee community (e.g., community leaders) to continue to educate refugees about the impact of COVID-19, how to protect oneself and others, the importance of contact tracing and what successful contact tracing requires, and how to manage and access care for COVID-19 and other health needs.

We believe implementation of these recommendations within health care settings may assist in reducing the impact of COVID-19 on resettled refugees and their communities.

\section{References}

1. Centers for Disease Control and Prevention. Guidelines for the U.S. domestic medical examination for newly arriving refugees. Accessed April 27th, 2020. https://www.cdc.gov/immigrantrefuge ehealth/guidelines/domestic/domestic-guidelines.html.

2. Garg S, et al. Hospitalization rates and characteristics of patients hospitalized with laboratory-confirmed coronavirus disease 2019-COVID-NET, 14 States, March 1-30, 2020. MMWR Morb Mortal Wkly Rep. 2020;69:458-64.

3. Fabio M, et al. Building on resiliencies of refugee families. Pediatr Clin N Am. 2019;66(3):655-67.

4. Flores G. The impact of medical interpreter services on the quality of health care: a systematic review. Med Care Res Rev. 2005;62(3):255-99.

5. CBC News. 'Everything is hard for us': newcomers in Canada find arrival complicated by COVID-19. 15 April 2020. Accessed May 10, 2020. https://www.cbc.ca/news/canada/british-columbia/ bc-settlement-services-newcomers-covid19-1.5531283.

6. Donahue M, Sreenivasan N, Stover D, et al. Notes from the Field: characteristics of meat processing facility workers with confirmed SARS-CoV-2 infection-Nebraska, April-May 2020. MMWR Morb Mortal Wkly Rep. 2020;69:1020-2.

7. Person B, et al. Fear and Stigma: The epidemic within the SARS Outbreak. Emerg Infect Dis. 2004;10(2):358-63.

8. Centers for Disease Control and Preventions. Vaccination Program for U.S.-Bound Refugees. Accessed April 27th, 2020. https ://www.cdc.gov/immigrantrefugeehealth/pdf/current-presumptiv e-immunization-schedules.pdf. 
9. World Health Organization. Measles-global situation. Accessed May 8, 2020. https://www.who.int/csr/don/26-november-2019measles-global_situation/en/.

10. Kozo J, et al. The partner relay communication network: sharing information during emergencies with limited english proficient populations. Health Secur. 2020;18:49-56.

11. Kaplan J. Hospitals have left many COVID-19 patients who don't speak english alone, confused and without proper care. ProPublica. 31 March 2020. Accessed May 10, 2020. https://www.propu blica.org/article/hospitals-have-left-many-covid19-patients-whodont-speak-english-alone-confused-and-without-proper-care?
12. Davidson N, et al. An issue of access: Delivering equitable health care for newly arrived refugee children in Australia. J Paediatr Child Health. 2004;40(9-10):569-75.

Publisher's Note Springer Nature remains neutral with regard to jurisdictional claims in published maps and institutional affiliations. 